in vivo $33: 1959-1965$ (2019)

doi:10.21873/invivo.11691

\title{
Prognostic Significance of Clinicopathological and Molecular Features After Neoadjuvant Chemoradiotherapy in Rectal Cancer Patients
}

\author{
HEE JEONG CHO ${ }^{1 *}$, JIN HO BAEK ${ }^{1 *}$, DONG WON BAEK ${ }^{1}$, BYUNG WOOG KANG ${ }^{1}$, SOO JUNG LEE ${ }^{1}$, \\ HYE JIN KIM ${ }^{2}$, SU YEON PARK ${ }^{2}$, JUN SEOK PARK ${ }^{2}$, GYU SEOG CHOI ${ }^{2}$ and JONG GWANG KIM ${ }^{1}$ \\ ${ }^{1}$ Department of Oncology/Hematology, Kyungpook National University Chilgok Hospital, \\ School of Medicine, Kyungpook National University, \\ Kyungpook National University Cancer Research Institute, Daegu, Republic of Korea; \\ ${ }^{2}$ Department of Surgery, Kyungpook National University Chilgok Hospital, \\ School of Medicine, Kyungpook National University, Daegu, Republic of Korea
}

\begin{abstract}
Background/Aim: This study evaluated clinicopathological and molecular features and their prognostic impact on patients with locally advanced rectal cancer (LARC) who received preoperative chemoradiotherapy $(C R T)$. Patients and Methods: We retrospectively gathered data from 284 patients with LARC who underwent total mesorectal excision (TME) after CRT. Results: In the univariate analysis, lower yield pathologic $T(y p T)$ category, yield pathologic $N(y p N)$ category, yield pathologic TNM (ypTNM) stage, as well as the absence of lymphovascular invasion (LVI) and perineural invasion (PNI), were significantly associated with better disease-free survival (DFS) and overall survival (OS). Meanwhile, the expression of $\mathrm{Ki}-67, \mathrm{p53}$, and the mismatch repair (MMR) status showed no association with clinical outcomes. A multivariate survival analysis revealed that ypT category and LVI were independent prognostic factors of a worse DFS (HR=3.081, p-value $=0.001$; $H R=2.818$, $p$-value $=0.030)$ and $O S(H R=3.158, p$-value $=0.006$; $H R=3.837$, $p$-value=0.014). Conclusion: The ypT category and the presence of LVI were found to be prognostic factors for patients with LARC after CRT followed by TME.
\end{abstract}

This article is freely accessible online.

*These Authors contributed equally to this work.

Correspondence to: Jong Gwang Kim, MD, Ph.D., Department of Oncology/Hematology, Kyungpook National University Chilgok Hospital, School of Medicine, Kyungpook National University, Kyungpook National University Cancer Research Institute, 807 Hogukno, Buk-gu, Daegu 41404, Republic of Korea. Tel: +82 532002623, Fax: +82 532002029, e-mail: jkk21c@knu.ac.kr

Key Words: Locally advanced rectal cancer, neoadjuvant chemoradiotherapy, prognostic factors.
Locally advanced rectal cancer (LARC), characterized by invasion of tumors beyond muscle layers or metastasis of regional lymph nodes at diagnosis, shows poor prognosis, and approximately one third of patients eventually experience distant metastases (1). Neoadjuvant chemoradiotherapy (CRT) in LARC is known to have advantages for anal sphincter preservation, preoperative downstaging of the tumor, lower local recurrence rate, and fewer toxicities related to treatment compared with adjuvant CRT $(1,2)$. Therefore, neoadjuvant CRT followed by surgical excision is recommended as standard treatment for patients with LARC.

Despite the adoption of neoadjuvant CRT in LARC management, the treatment response has remained varied. Around $15 \%$ of patients treated with neoadjuvant CRT achieve pathologic complete response (pCR), with the remaining of them exhibiting various pathologic responses from tumor downstaging to distant metastatic disease. The varied treatment responses imply that rectal cancer is a heterogeneous disease, and its unidentified clinicopathological features may be responsible for the different clinical outcomes such as recurrence, metastasis, or survival.

Pathological stages after surgical resection and following neoadjuvant CRT are universally classified by ypStage, which has been considered a robust prognostic indicator of LARC $(3,4)$. In addition, pathological residual lymph node metastasis and invasion depth of the tumor after neoadjuvant CRT have been confirmed to be major prognostic factors of rectal cancer and are strongly correlated with metastasis and disease-free survival (DFS) (3-6). Previous studies have demonstrated that the presence of lymphovascular invasion (LVI), or perineural invasion (PNI), has a negative impact on clinical long-term outcomes (7). Recently, molecular markers were studied as prognostic factors to predict CRT response and survival outcome in 
Table I. Patient and tumor characteristics.

\begin{tabular}{|c|c|}
\hline Characteristics & No. of patients $(n=284)$ \\
\hline \multicolumn{2}{|l|}{ Age } \\
\hline Median (range) & $59(25-88)$ \\
\hline \multicolumn{2}{|l|}{ Gender, n (\%) } \\
\hline Female & $86(30.3 \%)$ \\
\hline Male & $198(69.7 \%)$ \\
\hline \multicolumn{2}{|c|}{ Clinical $\mathrm{T}$ stage, $\mathrm{n}(\%)$} \\
\hline $\mathrm{cT} 2$ & $15(5.3 \%)$ \\
\hline $\mathrm{cT} 3$ & $228(80.3 \%)$ \\
\hline cT4 & $41(14.4 \%)$ \\
\hline \multicolumn{2}{|c|}{ Clinical $\mathrm{N}$ stage, $\mathrm{n}(\%)$} \\
\hline $\mathrm{cNO}$ & $44(15.5 \%)$ \\
\hline $\mathrm{cN} 1$ & $95(33.5 \%)$ \\
\hline $\mathrm{cN} 2$ & $145(51.1 \%)$ \\
\hline \multicolumn{2}{|c|}{ Clinical Stage, n (\%) } \\
\hline Stage II & $43(15.1 \%)$ \\
\hline Stage III & $241(84.9 \%)$ \\
\hline \multicolumn{2}{|c|}{ Pathologic T stage, n (\%) } \\
\hline урт0 & $40(14.1 \%)$ \\
\hline ypT1 & $8(2.8 \%)$ \\
\hline урт2 & $51(18.0 \%)$ \\
\hline урT3 & $172(60.6 \%)$ \\
\hline урT4 & $13(4.5 \%)$ \\
\hline \multicolumn{2}{|c|}{ Pathologic N stage, n (\%) } \\
\hline ypNo & $195(68.7 \%)$ \\
\hline ypN1 & $62(21.8 \%)$ \\
\hline ypN2 & $27(9.5 \%)$ \\
\hline \multicolumn{2}{|c|}{ Pathologic M stage, n (\%) } \\
\hline урм0 & $277(97.5 \%)$ \\
\hline урM1 & $7(2.5 \%)$ \\
\hline \multicolumn{2}{|c|}{ Pathologic Stage, n (\%) } \\
\hline ypStage 0 & $39(13.7 \%)$ \\
\hline ypStage I & $51(18.0 \%)$ \\
\hline ypStage II & $99(34.9 \%)$ \\
\hline ypStage III & $88(31.0 \%)$ \\
\hline ypStage IV & $7(2.5 \%)$ \\
\hline
\end{tabular}

LARC. A higher Ki-67 index has been associated with poor CRT response and survival outcomes in several studies (810). p53, which has been largely studied as a tumor suppressor in other cancers, has not been verified to have a prognostic impact on survival in LARC (11). In addition, microsatellite instability (MSI) caused by the loss of DNAmismatch repair (MMR) function, is known to have a negative predictive effect on survival of colon cancer patients treated with surgery followed by 5-fluorouracil (5FU)-based adjuvant chemotherapy $(12,13)$. However, the predictive role of MSI after neoadjuvant CRT in rectal cancer remains controversial (14-16).

In this study, we investigated the prognostic significance of clinicopathological features, including pathological and molecular characteristics, in patients with LARC treated with neoadjuvant CRT, followed by surgical excision.

\begin{tabular}{|c|c|}
\hline Characteristics & No. of patients $(n=284)$ \\
\hline TRG, n (\%) & $\mathrm{n}=147$ \\
\hline TRG 4 & $40(27.2 \%)$ \\
\hline TRG 3 & $49(33.3 \%)$ \\
\hline TRG 2 & $29(19.7 \%)$ \\
\hline TRG 1 & $24(16.3 \%)$ \\
\hline TRG 0 & $5(3.4 \%)$ \\
\hline \multicolumn{2}{|l|}{ LVI, n (\%) } \\
\hline No & $248(87.3 \%)$ \\
\hline Yes & $36(12.7 \%)$ \\
\hline \multicolumn{2}{|l|}{ PNI, n (\%) } \\
\hline No & $237(83.5 \%)$ \\
\hline Yes & $47(16.5 \%)$ \\
\hline $\mathrm{Ki}-67, \mathrm{n}(\%)$ & $\mathrm{n}=192$ \\
\hline Negative & $14(7.3 \%)$ \\
\hline Positive & $178(92.7 \%)$ \\
\hline $\mathrm{p} 53, \mathrm{n}(\%)$ & $n=191$ \\
\hline Negative & $61(31.9 \%)$ \\
\hline Positive & $130(68.1 \%)$ \\
\hline MMR status, n (\%) & $\mathrm{n}=194$ \\
\hline MSI-H & $34(18.2 \%)$ \\
\hline MSI-L/MSS & $153(81.8 \%)$ \\
\hline \multicolumn{2}{|l|}{ Recurrence, n (\%) } \\
\hline No & $189(66.5 \%)$ \\
\hline Local recurrence & $5(1.8 \%)$ \\
\hline Distant recurrence & $71(25.0 \%)$ \\
\hline Local \& Distant recurrence & $19(6.7 \%)$ \\
\hline \multicolumn{2}{|l|}{ Death, $\mathrm{n}(\%)$} \\
\hline No & $195(68.7 \%)$ \\
\hline Yes & $89(31.3 \%)$ \\
\hline
\end{tabular}

CR: Complete remission; TRG: tumor regression grade; LVI: lymphovascular invasion; PNI: perineural invasion; MMR: mismatch repair; MSI-H: microsatellite instability-high; MSI-L: microsatellite instability-low; MSS: microsatellite stable.

\section{Patients and Methods}

Patients and treatment. We retrospectively reviewed medical records from 284 patients with LARC who underwent neoadjuvant CRT followed by surgical excision at Kyungpook National University Chilgok Hospital (KNUCH, Daegu, Korea) between January 2006 and October 2015. The patients were enrolled in the study if they were (a) pathologically diagnosed with primary rectal cancer, (b) in clinical stage II or III rectal cancer as classified by the seventh edition of American Joint Committee on Cancer staging system (17), and (c) treated with neoadjuvant CRT, followed by surgical excision.

All patients received $45 \mathrm{~Gy} \sim 50$ Gy of radiation delivered in 25 daily fractions over 5 weeks with a concurrent $400 \mathrm{mg} / \mathrm{m}^{2}$ intravenous dose of 5 -FU and $20 \mathrm{mg} / \mathrm{m}^{2}$ of leucovorin on days $1-4$ and $29-32$, or oral capecitabine $\left(825 \mathrm{mg} / \mathrm{m}^{2}\right)$ twice daily for 5 days per week for 5 weeks. Dose reduction was individualized according to the performance status, toxicities, or medical condition of 
patients. The total mesorectal excision (TME) was performed $6 \sim 8$ weeks after the completion of neoadjuvant CRT.

Pathological characteristics and molecular pathological features. All surgically resected specimens were examined by pathologists at $\mathrm{KNUCH}$. The pathologic reports included ypT stage, ypN stage, LVI, and PNI. For assessment of tumor regression (TRG), the following Dworak grading system was used: the Dworak regression Grade 0 (TRG 0)=no regression; Grade 1 (TRG 1)=dominant tumor mass with obvious fibrosis and/or vasculopathy; Grade 2 (TRG 2)=dominantly fibrotic changes with few tumor cells or groups (easy to find); Grade 3 (TRG 3)=very few tumor cells in fibrotic tissue with or without mucous substance (difficult to find microscopically); and Grade 4 (TRG 4)=no tumor cells, only fibrotic mass (18). We performed immunohistochemical (IHC) studies for Ki-67 and p53 protein using an autoimmunostainer (Ventana Medical Systems, Tucson, AZ, USA) in accordance with the manufacturer's instructions. When more than $10 \%$ of the tumor cells were stained, the tumor was considered as positive for $\mathrm{Ki}-67$ and $\mathrm{p} 53$. Microsatellite instability (MSI) was evaluated by IHC analysis of DNA mismatch repair proteins $(M L H 1, M S H 2, M S H 6$, and PMS2) $(19,20)$. IHC for MMR protein expression was performed on whole sections using an automatic immunostainer (BenchMark XT, Ventana Medical Systems, Tucson, AZ, USA) according to the manufacturer's instructions. Tumors displaying loss of expression of one or more MMR proteins were considered to be MSI-high (MSI-H), whereas those with intact MMR proteins were classified as MSI-L/microsatellite stable (MSS) (21).

Ethical approval. All procedures performed in studies involving human participants were in accordance with the ethical standards of the institutional and/or national research committee and with the 1964 Declaration of Helsinki and its later amendments or comparable ethical standards.

Statistical analysis. The characteristics of patients were described using proportions and medians. DFS was measured from date of diagnosis to the date of proven local recurrence, distant metastasis, or death by any cause. Overall survival (OS) was calculated from the date of diagnosis to death. Data were censored if patients were free of recurrence or still alive at the last follow-up. We used the Kaplan-Meier method to estimate the DFS and OS, and the log rank test, according to selected prognostic variables, to compare the survival curves. Multivariate survival analyses were carried out using the Cox proportional hazard regression model, and the hazard ratio (HR) and 95\% confidence interval (CI) for each variable were estimated. A $p$-value of less than 0.05 was considered statistically significant. The statistical analysis was performed using SPSS for Windows (version 19.0 SPSS Inc., Chicago, IL, USA).

\section{Results}

Patient and tumor characteristics. The patient and tumor characteristics are summarized in Table I. The median age was 59 years (range $=25-88$ years) at the time of diagnosis. The outcome of patients based on the pathologic stages yielded after neoadjuvant CRT were as follows: ypStage 0
Table II. Kaplan-Meier for disease-free survival and overall survival.

\begin{tabular}{|c|c|c|c|c|c|}
\hline Variables & $\begin{array}{l}\text { No. of } \\
\text { patients }\end{array}$ & $\begin{array}{c}\text { 5-year } \\
\text { DFS (\%) }\end{array}$ & $p$-Value & $\begin{array}{c}5 \text {-year } \\
\text { OS (\%) }\end{array}$ & $p$-Value \\
\hline Overall & 284 & 61.4 & & 74.8 & \\
\hline Age & & & 0.293 & & 0.087 \\
\hline$<59$ & 132 & 65.1 & & 76.5 & \\
\hline$\geq 59$ & 152 & 58.3 & & 73.1 & \\
\hline Gender & & & 0.917 & & 0.905 \\
\hline Female & 86 & 60.0 & & 77.6 & \\
\hline Male & 198 & 61.9 & & 73.5 & \\
\hline ypStage & & & $<0.001$ & & $<0.001$ \\
\hline ypStage 0-1 & 90 & 83.3 & & 91.0 & \\
\hline ypStage 2 & 99 & 64.1 & & 77.2 & \\
\hline ypStage 3-4 & 95 & 42.2 & & 57.0 & \\
\hline ypN & & & $<0.001$ & & $<0.001$ \\
\hline ypNO & 195 & 71.9 & & 82.0 & \\
\hline ypN1-2 & 89 & 38.6 & & 59.0 & \\
\hline ypT & & & $<0.001$ & & $<0.001$ \\
\hline урт0-2 & 99 & 81.7 & & 89.7 & \\
\hline урТ3-4 & 185 & 50.6 & & 66.8 & \\
\hline TRG & & & 0.015 & & 0.131 \\
\hline TRG 4-3 & 89 & 76.3 & & 84.5 & \\
\hline TRG 2-0 & 58 & 56.5 & & 78.3 & \\
\hline LVI & & & 0.001 & & 0.001 \\
\hline No & 248 & 65.4 & & 77.7 & \\
\hline Yes & 36 & 35.9 & & 55.6 & \\
\hline PNI & & & $<0.001$ & & $<0.001$ \\
\hline No & 237 & 66.4 & & 78.8 & \\
\hline Yes & 47 & 35.3 & & 52.4 & \\
\hline $\mathrm{Ki}-67$ & & & 0.325 & & 0.672 \\
\hline Negative & 14 & 78.6 & & 76.0 & \\
\hline Positive & 178 & 57.0 & & 74.2 & \\
\hline $\mathrm{p} 53$ & & & 0.755 & & 0.543 \\
\hline Negative & 61 & 59.1 & & 71.0 & \\
\hline Positive & 130 & 60.3 & & 77.0 & \\
\hline MMR status & & & 0.802 & & 0.404 \\
\hline MSI-H & 34 & 61.3 & & 71.0 & \\
\hline MSI-L/MSS & 153 & 57.5 & & 75.0 & \\
\hline
\end{tabular}

DFS: Disease-free survival; OS: overall survival; TRG: tumor regression grade; LVI: lymphovascular invasion; PNI: perineural invasion; MMR: mismatch repair; MSI-H: microsatellite instabilityhigh; MSI-L: microsatellite instability-low; MSS: microsatellite stable.

$(\mathrm{n}=39,13.7 \%)$, ypStage I $(\mathrm{n}=51,18.0 \%)$, ypStage II $(\mathrm{n}=99$, $34.9 \%)$ and ypStage III $(n=88,31.0 \%)$. Seven patients $(2.5 \%)$ were diagnosed with ypStage IV. Among a total of 284 patients, 147 patients were examined for classification according to the Dworak grading system. The rate of patients with TRG 4, which implies complete pathologic regression of the primary tumor, was $27.2 \%(n=40)$. The number of patients with the presence of LVI and PNI was $36(12.7 \%)$ and $47(16.5 \%)$, respectively. Local or distant recurrence occurred in $33.4 \%(\mathrm{n}=95)$ of cases, and 89 patients $(31.3 \%)$ died during the follow-up period. 

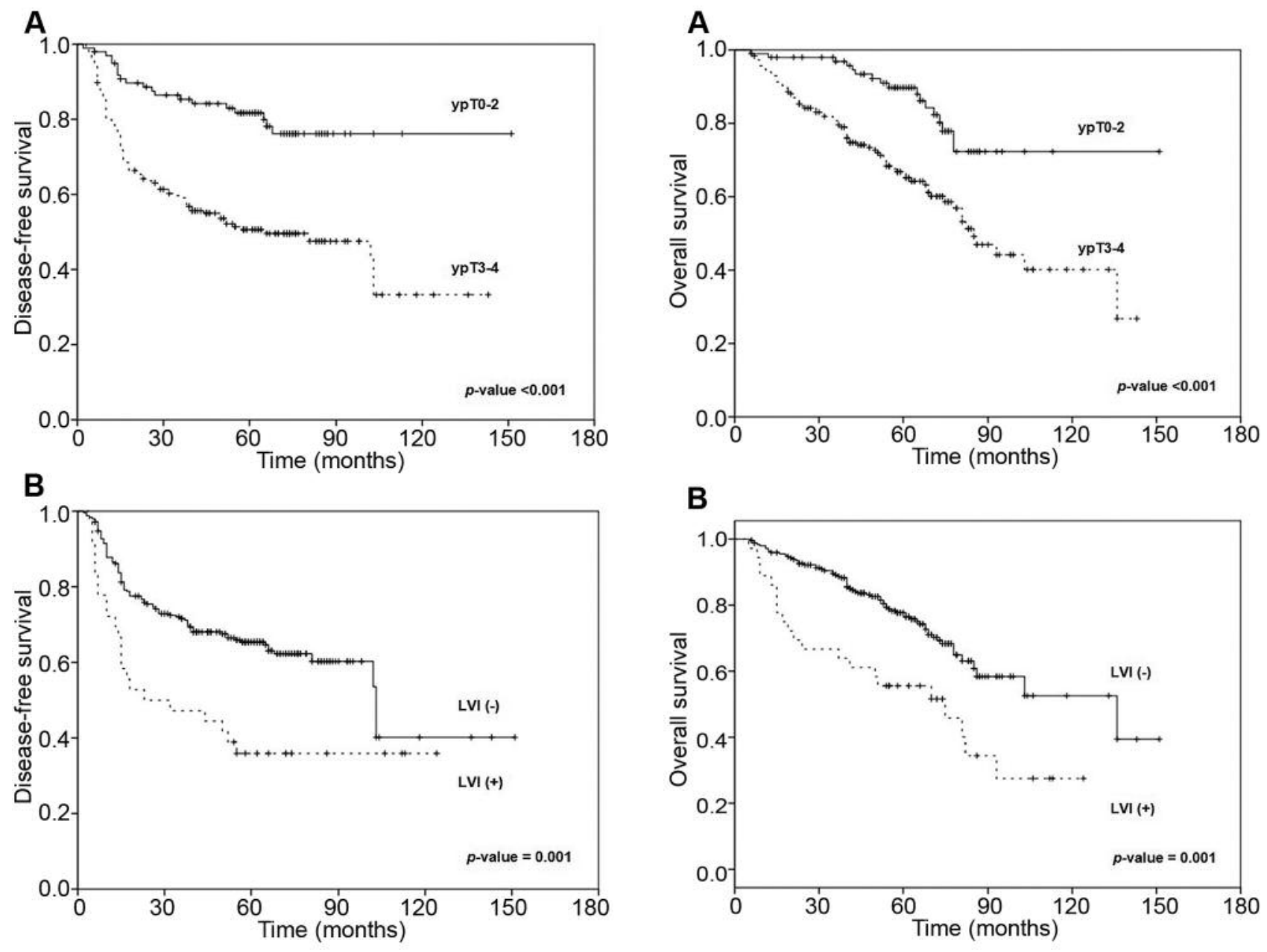

B

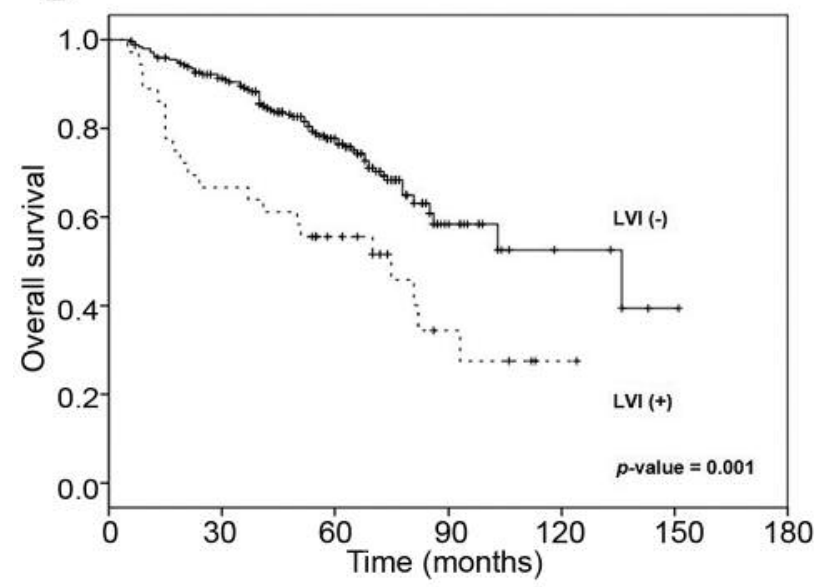

Figure 1. Kaplan-Meier survival curves for disease-free survival (DFS) accoring to (A) ypT category and (B) presence of lymphovascular invasion (LVI) in locally advanced rectal cancer (LARC) patients who underwent neoadjuvant chemoradiotherapy (CRT).

Prognostic value of pathological features affecting survival outcomes. The results of the survival analysis are described in Table II. In a median follow-up duration of 60 months (5-151 months), the estimated 5-year DFS and OS were $61.4 \%$ and $74.5 \%$ for all patients, respectively. In the univariate survival analysis, the ypStage was found to be strongly associated with the survival of LARC patients ( $p$-value $<0.001$ for both 5 -year DFS and OS). Patients with the presence of ypN had significantly inferior DFS and OS compared to those who had negative residual lymph nodes after neoadjuvant CRT (5-year DFS: $71.9 \%$ vs. 38.6\%, $p$-value $<0.001$; 5-year OS: $82.0 \%$ vs. 59.0\%, $p$-value $<0.001)$. Tumors penetrating muscle layers and visceral peritoneum, which were categorized as ypT3-4, showed significantly lower survival rates than the ypT0-2 category, in which

Figure 2. Kaplan-Meier survival curves for overall survival (OS) accoring to (A) ypT category and (B) presence of lymphovascular invasion (LVI) in locally advanced rectal cancer (LARC) patients who underwent neoadjuvant chemoradiotherapy (CRT).

tumors were confined below the muscle layers (5-year DFS: $81.7 \%$ vs. $50.6 \%, p$-value $<0.001$; 5-year OS: $89.7 \%$ vs. $66.8 \%, p$-value $<0.001$ ) (Figure 1A and B). Five-year DFS rates of the poor treatment response group (categorized as TRG 2-0) were inferior to the TRG 4-3 category, which was considered a good treatment response group $(76.3 \%$ vs. $56.5 \%, p$-value $=0.015)$. Pathological characteristics including LVI and PNI were statistically significant prognostic factors for both 5-year DFS (LVI: $65.4 \%$ vs. 35.9\%, $p$-value $=0.001$; PNI: $66.4 \%$ vs. $36.9 \%, p$-value $<0.001$ ) and OS (LVI: $77.7 \%$ vs. $55.6 \%, p$-value $=0.001$; PNI: $78.8 \%$ vs. $52.4 \%$, $p$-value $<0.001$ ) (Figure 2A and B).

Molecular features and survival outcomes. We performed IHC studies for Ki-67 and p53 on the viable tumor cells of 
Table III. Multivariate analysis of disease-free survival and overall survival.

\begin{tabular}{|c|c|c|c|c|c|c|}
\hline & \multicolumn{3}{|c|}{ DFS } & \multicolumn{3}{|c|}{ OS } \\
\hline & HR & $95 \% \mathrm{CI}$ & $p$-Value & HR & $95 \% \mathrm{CI}$ & $p$-Value \\
\hline Age & 1.019 & $0.992-1.047$ & 0.177 & 1.033 & $0.998-1.069$ & 0.064 \\
\hline ypN0 vs. ypN1-2 & 1.390 & $0.682-2.831$ & 0.365 & 0.776 & $0.307-1.961$ & 0.592 \\
\hline урТ0-2 vs. урТ3-4 & 3.081 & $1.593-5.960$ & 0.001 & 3.158 & $1.397-7.137$ & 0.006 \\
\hline TRG 4-3 vs. TRG 2-0 & 1.300 & $0.697-2.427$ & 0.409 & 1.191 & $0.548-2.589$ & 0.659 \\
\hline LVI No vs. Yes & 2.818 & $1.108-7.162$ & 0.030 & 3.837 & $1.318-11.168$ & 0.014 \\
\hline PNI No vs. Yes & 1.573 & $0.707-3.498$ & 0.267 & 1.286 & $0.399-4.139$ & 0.673 \\
\hline
\end{tabular}

DFS: Disease-free survival; OS: overall survival; CI: confidence interval; TRG: tumor regression grade; LVI: lymphovascular invasion; PNI: perineural invasion.

surgical specimens; positive staining was observed in $92.7 \%$ $(n=178)$ and $68.1 \%(n=130)$ of samples, respectively. In 194 patients who evaluated the loss of MMR proteins expression, $34(18.2 \%)$ patients showed loss of expression of at least one MMR protein, sorting to MSI-H group, and 153 (81.8\%) patients without loss of expression of at least one MMR were classified as MSI-L/MSS. The survival analysis showed that the expression of Ki-67, p53 and the MMR proteins after neoadjuvant CRT were not significantly associated with survival outcomes.

Multivariate survival analyses. ypT, ypN, TRG, LVI and PNI, and age were included in the multivariate survival analyses. Among them, depth of tumor invasion, ypT0-2 versus ypT3-4, and the presence of LVI were identified as significant independent prognostic factors for DFS (ypT0-2 vs. ypT3-4: $\mathrm{HR}=3.081,95 \% \mathrm{CI}=1.593-5.960, p$-value $=0.001$; LVI: $H R=2.818,95 \% \mathrm{CI}=1.108-7.162, p$-value $=0.030)$ and OS (ypT0-2 vs. ypT3-4: HR=3.158, 95\%CI=1.397-7.137, $p$ value $=0.006$; $\mathrm{LVI}: \mathrm{HR}=3.837,95 \% \mathrm{CI}=1.318-11.168, p$ value $=0.014$; Table III).

\section{Discussion}

In the current study, we investigated the prognostic impact of the clinicopathological features including Ki-67, p53, and MSI status in LARC patients who underwent TME after neoadjuvant CRT. Patients in the high ypT category and those with LVI showed significantly poor survival outcomes. Meanwhile, molecular markers including expression of $\mathrm{Ki}$ 67 and p53 and the MMR status failed to confirm their prognostic values in LARC patients.

The pathological response after neoadjuvant CRT, including ypT, ypN as well as TRG, has already been reported to be associated with disease recurrence, distant metastasis, and survival in a German multicenter randomized clinical trial that investigated the efficacy of neoadjuvant CRT compared to postoperative CRT in patients with clinical T3-4 or any node-positive rectal cancer (6). Moreover, a number of studies have consistently demonstrated the negative effect of the presence of LVI in rectal cancer survival (7). Lymphatic and vascular structures are considered the main route of spreading of tumor cells. Although it is not fully understood how tumor cells invade lymphatic and vascular vessels, tumor cells that infiltrate lymphatic and vascular structures tend to disseminate to lymph nodes and distant sites (22). This supports the conclusion that the presence of LVI is a potentially unreliable prognostic marker in rectal cancer. Recently, several researchers have attempted to examine whether adjuvant chemotherapy for LARC patients with the presence of LVI and/or PNI after neoadjuvant CRT contributed to favorable survival outcomes. They found that adjuvant chemotherapy resulted in better survival outcomes in the presence of PNI than LVI $(23,24)$. The strategy of LARC management is moving toward a more tailored treatment that involves stratification of patients according to the possibility to benefit from adjuvant chemotherapy in order to prevent distant metastasis and eventually improving survival. Based on these results, the ypT category and the presence of LVI could be useful indicators for stratifying risk and determining adjuvant chemotherapy in LARC patients who underwent neoadjuvant CRT followed by TME.

The prognostic impact of Ki-67 and p53 expression has already been determined in several cancers $(8,25,26)$. In particular, high expression of Ki-67 suggests high sensitivity to radiation, which contributes to a favorable response of radiotherapy in radio-sensitive tumors, such as small-cell lung cancer or cervical cancer $(25,26)$. However, the prognostic role of $\mathrm{Ki}-67$ and p53 expression in LARC remains controversial $(8,9,11,27,28)$. In several studies, samples obtained before CRT were used to interpret the degree of expression in $\operatorname{IHC}(8,27)$. However, expression of 
Ki-67 and p53 in this study was examined using operative specimens after neoadjuvant CRT, rather than before treatment. Therefore, there may have been differences in the time of sample acquisition between the specimens used to detect the expression using IHC. In addition, the methodology of IHC will need to be standardized. Furthermore, the correlation between the expression of Ki67 and sensitivity to radiation was not estimated in the present study.

MSI is a well-known prognostic and predictive biomarker in colon cancer. Its strong association with favorable prognosis and poor response to 5-FU chemotherapy has necessitated adjuvant chemotherapy in low-risk stage II colon cancer (12). However, the role of MSI as a predictive factor in rectal cancer has not been confirmed (29). Some studies have reported that MSI-H was independently associated with poor pCR rates after neoadjuvant CRT (15), and had inferior survival outcomes for rectal cancer (14). In contrast, other studies have reported that patients with MSI-H or dMMR rectal cancer had higher survival rates $(16,30)$. These contradictory results regarding MSI as a predictive factor may be attributable to the mixed rectal cancer phenotypes with patients harboring various concomitant mutations in different genes such as BRAF, KRAS, or other cancer pathway genes that generally show poor prognosis $(15,29)$. In the meantime, the MSI status from surgically resected specimens after neoadjuvant CRT was not associated with survival outcomes in the present study. Therefore, further studies are warranted to evaluate the predictive effect of MSI status after CRT in LARC.

In conclusion, the ypT category and the presence of LVI had a significant prognostic impact in patients with LARC. However, the expression of Ki-67, p53, and MMR status were not associated with survival outcomes after neoadjuvant CRT. Therefore, additional studies on the molecular features after preoperative CRT are warranted for the development of precision medicine in LARC.

\section{Conflicts of Interest}

The Authors declare that they have no conflicts of interest in regard to this study.

\section{Authors' Contributions}

All Authors contributed to the design and implementation of the research, to the analysis of the results, and the writing of the article.

\section{Acknowledgements}

This work was supported by the National Research Foundation of Korea (NRF) Grant funded by the Korea government (2014R1 A5A2009242).

\section{References}

1 Sauer R, Becker H, Hohenberger W, Rodel C, Wittekind C, Fietkau R, Martus P, Tschmelitsch J, Hager E, Hess CF, Karstens $\mathrm{JH}$, Liersch T, Schmidberger H and Raab R: Preoperative versus postoperative chemoradiotherapy for rectal cancer. N Engl J Med 351(17): 1731-1740, 2004. PMID: 15496622. DOI: 10.1056/NEJMoa040694

2 Milinis K, Thornton M, Montazeri A and Rooney PS: Adjuvant chemotherapy for rectal cancer: Is it needed? World J Clin Oncol 6(6): 225-236, 2015. PMID: 26677436. DOI: 10.5306/wjco. v6.i6.225

3 Omejc $\mathrm{M}$ and Potisek M: Prognostic significance of tumor regression in locally advanced rectal cancer after preoperative radiochemotherapy. Radiol Oncol 52(1): 30-35, 2018. PMID: 29520203. DOI: 10.1515/raon-2017-0059

4 Lee SY, Jo JS, Kim HJ, Kim CH, Kim YJ and Kim HR: Prognostic factors for low rectal cancer patients undergoing intersphincteric resection after neoadjuvant chemoradiation. J Surg Oncol 111(8): 1054-1058, 2015. PMID: 25977149. DOI: $10.1002 /$ jso. 23932

5 Mechera R, Schuster T, Rosenberg R and Speich B: Lymph node yield after rectal resection in patients treated with neoadjuvant radiation for rectal cancer: A systematic review and metaanalysis. Eur J Cancer 72: 84-94, 2017. PMID: 28027520. DOI: 10.1016/j.ejca.2016.10.031

6 Fokas E, Liersch T, Fietkau R, Hohenberger W, Beissbarth T, Hess C, Becker H, Ghadimi M, Mrak K, Merkel S, Raab HR, Sauer R, Wittekind C and Rodel C: Tumor regression grading after preoperative chemoradiotherapy for locally advanced rectal carcinoma revisited: Updated results of the cao/aro/aio-94 trial. J Clin Oncol 32(15): 1554-1562, 2014. PMID: 24752056. DOI: 10.1200/jco.2013.54.3769

7 Kong JC, Guerra GR, Warrier SK, Lynch AC, Michael M, Ngan SY, Phillips W, Ramsay G and Heriot AG: Prognostic value of tumour regression grade in locally advanced rectal cancer: A systematic review and meta-analysis. Colorectal Dis 20(7): 574585, 2018. PMID: 29582537. DOI: 10.1111/codi.14106

8 Kim NK, Park JK, Lee KY, Yang WI, Yun SH, Sung J and Min JS: P53, bcl-2, and ki-67 expression according to tumor response after concurrent chemoradiotherapy for advanced rectal cancer. Ann Surg Oncol 8(5): 418-424, 2001. PMID: 11407516. DOI: 10.1007/s10434-001-0418-5

9 Yoshikawa K, Shimada M, Higashijima J, Nakao T, Nishi M, Takasu C, Kashihara H, Eto S and Bando Y: Ki-67 and survivin as predictive factors for rectal cancer treated with preoperative chemoradiotherapy. Anticancer Res 38(3): 1735-1739, 2018. PMID: 29491110. DOI: 10.21873/anticanres.12409

10 Jafarian AH, Kermani AT, Esmaeili J, Roshan NM, SeilanianToosi M, Omidi AA and Shahri MK: The role of cox-2 and ki67 over-expression in the prediction of pathologic response of rectal cancer to neoadjuvant chemoradiation therapy. Indian $\mathrm{J}$ Cancer 53(4): 548-551, 2016. PMID: 28485348. DOI: 10.4103/ 0019-509x.204770

$11 \mathrm{Kim}$ NK and Hur H: New perspectives on predictive biomarkers of tumor response and their clinical application in preoperative chemoradiation therapy for rectal cancer. Yonsei Med J 56(6): 14611477, 2015. PMID: 26446626. DOI: 10.3349/ymj.2015.56.6.1461

12 Ribic CM, Sargent DJ, Moore MJ, Thibodeau SN, French AJ, Goldberg RM, Hamilton SR, Laurent-Puig P, Gryfe R, Shepherd 
LE, Tu D, Redston M and Gallinger S: Tumor microsatelliteinstability status as a predictor of benefit from fluorouracil-based adjuvant chemotherapy for colon cancer. N Engl J Med 349(3): 247-257, 2003. PMID: 12867608. DOI: 10.1056/NEJMoa022289

13 Kim JE, Hong YS, Kim HJ, Kim KP, Lee JL, Park SJ, Lim SB, Park IJ, Kim CW, Yoon YS, Yu CS, Kim JC, Hoon KJ and Kim TW: Defective mismatch repair status was not associated with $\mathrm{dfs}$ and os in stage ii colon cancer treated with adjuvant chemotherapy. Ann Surg Oncol 22: S630-637, 2015. PMID: 26271397. DOI: $10.1245 / \mathrm{s} 10434-015-4807-6$

14 Samowitz WS, Curtin K, Wolff RK, Tripp SR, Caan BJ and Slattery ML: Microsatellite instability and survival in rectal cancer. Cancer Causes Control 20(9): 1763-1768, 2009. PMID: 19669908. DOI: 10.1007/s10552-009-9410-3

15 Hasan S, Renz P, Wegner RE, Finley G, Raj M, Monga D, McCormick J and Kirichenko A: Microsatellite instability (MSI) as an independent predictor of pathologic complete response (PCR) in locally advanced rectal cancer: A national cancer database (NCDB) analysis. Ann Surg, 2018. PMID: 30216221. DOI: $10.1097 /$ sla.0000000000003051

16 de Rosa N, Rodriguez-Bigas MA, Chang GJ, Veerapong J, Borras E, Krishnan S, Bednarski B, Messick CA, Skibber JM, Feig BW, Lynch PM, Vilar E and You YN: DNA mismatch repair deficiency in rectal cancer: Benchmarking its impact on prognosis, neoadjuvant response prediction, and clinical cancer genetics. J Clin Oncol 34(25): 3039-3046, 2016. PMID: 27432916. DOI: $10.1200 /$ jco.2016.66.6826

17 Edge SB and Compton CC: The american joint committee on cancer: The 7th edition of the ajcc cancer staging manual and the future of tnm. Ann Surg Oncol 17(6): 1471-1474, 2010. PMID: 20180029. DOI: 10.1245/s10434-010-0985-4

18 Dworak O, Keilholz L and Hoffmann A: Pathological features of rectal cancer after preoperative radiochemotherapy. Int J Colorectal Dis 12(1): 19-23, 1997. PMID: 9112145.

19 Lindor NM, Burgart LJ, Leontovich O, Goldberg RM, Cunningham JM, Sargent DJ, Walsh-Vockley C, Petersen GM, Walsh MD, Leggett BA, Young JP, Barker MA, Jass JR, Hopper J, Gallinger S, Bapat B, Redston $M$ and Thibodeau SN: Immunohistochemistry versus microsatellite instability testing in phenotyping colorectal tumors. J Clin Oncol 20(4): 1043-1048, 2002. PMID: 11844828. DOI: 10.1200/JCO.2002.20.4.1043

20 Rodel C, Martus P, Papadoupolos T, Fuzesi L, Klimpfinger M, Fietkau R, Liersch T, Hohenberger W, Raab R, Sauer R and Wittekind C: Prognostic significance of tumor regression after preoperative chemoradiotherapy for rectal cancer. J Clin Oncol 23(34): 8688-8696, 2005. PMID: 16246976. DOI: 10.1200/ jco.2005.02.1329

21 Bellizzi AM and Frankel WL: Colorectal cancer due to deficiency in DNA mismatch repair function: A review. Adv Anat Pathol 16(6): 405-417, 2009. PMID: 19851131. DOI: 10.1097/PAP.0b013e3181bb6bdc

22 Schoppmann SF, Bayer G, Aumayr K, Taucher S, Geleff S, Rudas M, Kubista E, Hausmaninger H, Samonigg H, Gnant M, Jakesz R and Horvat R: Prognostic value of lymphangiogenesis and lymphovascular invasion in invasive breast cancer. Ann Surg 240(2): 306-312, 2004. PMID: 15273556. DOI: 10.1097/ 01.sla.0000133355.48672.22
23 Song JH, Yu M, Kang KM, Lee JH, Kim SH, Nam TK, Jeong JU, Jang HS, Lee JW and Jung JH: Significance of perineural and lymphovascular invasion in locally advanced rectal cancer treated by preoperative chemoradiotherapy and radical surgery: Can perineural invasion be an indication of adjuvant chemotherapy? Radiother Oncol 133: 125-131, 2019. PMID: 30935568. DOI: 10.1016/j.radonc.2019.01.002

24 Sun Q, Liu T, Liu P, Luo J, Zhang N, Lu K, Ju H, Zhu Y, Wu W, Zhang L, Fan Y, Liu Y, Li D, Zhu Y and Liu L: Perineural and lymphovascular invasion predicts for poor prognosis in locally advanced rectal cancer after neoadjuvant chemoradiotherapy and surgery. J Cancer 10(10): 2243-2249, 2019. PMID: 31258728. DOI: $10.7150 /$ jca.31473

25 Ishibashi N, Maebayashi T, Aizawa T, Sakaguchi M, Nishimaki $\mathrm{H}$ and Masuda S: Correlation between the ki-67 proliferation index and response to radiation therapy in small cell lung cancer. Radiat Oncol 12(1): 16, 2017. PMID: 28086989. DOI: 10.1186/ s13014-016-0744-1

26 Nakano T and Oka K: Differential values of ki-67 index and mitotic index of proliferating cell population. An assessment of cell cycle and prognosis in radiation therapy for cervical cancer. Cancer 72(8): 2401-2408, 1993. PMID: 8402456. DOI: 10.1002/10970142(19931015)72:8<2401::aid-cncr2820720818>3.0.co;2-d

27 Rau B, Sturm I, Lage H, Berger S, Schneider U, Hauptmann S, Wust P, Riess H, Schlag PM, Dorken B and Daniel PT: Dynamic expression profile of $\mathrm{p} 21 \mathrm{waf} 1 / \mathrm{cip} 1$ and ki-67 predicts survival in rectal carcinoma treated with preoperative radiochemotherapy. J Clin Oncol 21(18): 3391-3401, 2003. PMID: 12885834. DOI: $10.1200 /$ jco.2003.07.077

28 Terzi C, Canda AE, Sagol O, Atila K, Sonmez D, Fuzun M, Gorken IB, Oztop I and Obuz F: Survivin, p53, and ki-67 as predictors of histopathologic response in locally advanced rectal cancer treated with preoperative chemoradiotherapy. Int $\mathrm{J}$ Colorectal Dis 23(1): 37-45, 2008. PMID: 17805549. DOI: 10.1007/s00384-007-0376-x

29 Hong SP, Min BS, Kim TI, Cheon JH, Kim NK, Kim H and Kim WH: The differential impact of microsatellite instability as a marker of prognosis and tumour response between colon cancer and rectal cancer. Eur J Cancer 48(8): 1235-1243, 2012. PMID: 22071131. DOI: 10.1016/j.ejca.2011.10.005

30 Colombino M, Cossu A, Manca A, Dedola MF, Giordano M, Scintu F, Curci A, Avallone A, Comella G, Amoruso M, Margari A, Bonomo GM, Castriota M, Tanda F and Palmieri G: Prevalence and prognostic role of microsatellite instability in patients with rectal carcinoma. Ann Oncol 13(9): 1447-1453, 2002. PMID: 12196371. DOI: 10.1093/annonc/mdf240
Received August 28, 2019

Revised September 21, 2019

Accepted September 23, 2019 